\title{
ORIGINAL ARTICLE Ageing with neurogenic bowel dysfunction
}

\author{
SD Nielsen ${ }^{1}$, PM Faaborg ${ }^{2}$, NB Finnerup ${ }^{3}$, P Christensen $^{2}$ and K Krogh ${ }^{1}$
}

Study design: Longitudinal study with postal survey.

Objectives: To describe changes in the patterns of neurogenic bowel dysfunction and bowel management in a population of people with spinal cord injury (SCl) followed for two decades.

Setting: Members of the Danish SCI Association.

Methods: In 1996, a validated questionnaire on bowel function was sent to the members of the Danish SCI Association $(n=589)$. The same questionnaire was sent to all the surviving members in $2006(n=284)$ and in $2015(n=178)$. A total of 109 responded to both the 1996 and 2015 questionnaires.

Results: Comparing data from 2015 with those from the exact same participants in 1996, the proportion of respondents needing more than $30 \mathrm{~min}$ for each defaecation increased from 21 to $39 \%(P<0.01)$, the use of laxatives increased $(P<0.05)$ and the proportion considering themselves very constipated increased from 19 to $31 \%(P<0.01)$. In contrast, the proportion suffering from faecal incontinence remained stable at 18\% in 1996 and 19\% in 2015. During the 19-year period, there had been no significant change in the methods for bowel care, but $22(20 \%)$ had undergone surgery for bowel dysfunction, including $11(10 \%)$ who had some form of stoma.

Conclusion: Self-assessed severity of constipation increased but quality of life remained stable in a cohort of people with SCl followed prospectively for 19 years. Methods for bowel care remained surprisingly stable but a large proportion had undergone stoma surgery. Spinal Cord (2017) 55, 769-773; doi:10.1038/sc.2017.22; published online 14 March 2017

\section{INTRODUCTION}

Spinal cord injury (SCI) has profound impact on bowel function. Colorectal transit time is prolonged, ${ }^{1,2}$ colorectal emptying at defaecation is reduced ${ }^{3,4}$ and anorectal sensation and voluntary control of the external anal sphincter is reduced or lost. 5,6 Consequently, most people with SCI suffer from neurogenic bowel dysfunction (NBD) including combinations of constipation, faecal incontinence and abdominal pain..$^{7-11}$ Symptoms of NBD restrict daily activities and impair quality of life (QoL). ${ }^{7,8}$

The life expectancy of people with paraplegia is close to that of the general population but is 10 years shorter in those with tetraplegia. Hence, more individuals will live to an older age with complications related to their SCI, including bowel dysfunction. However, little is known about the actual changes in bowel function and bowel management experienced by individuals who have lived with SCI over recent decades. In that period of time, the knowledge about NBD has increased significantly. New treatment modalities including transanal irrigation ${ }^{12}$ and sacral nerve stimulation have been introduced. ${ }^{13}$ An NBD score ${ }^{14}$ and International SCI Bowel Function Data Sets have been developed. ${ }^{15,16}$ Multifaceted programs for treatment have been proposed. ${ }^{17,18}$ Such programs usually include non-pharmacological treatment, laxatives, prokinetics and transanal irrigation. ${ }^{17,18}$ Surgery is reserved to patients not responding to conservative treatment or to the elderly or patients with poor hand function. It is, however, unknown to what degree increased awareness and new treatment modalities have changed clinical practice and, ultimately, the daily life of patients.

In 1996, we described bowel function in a cohort of 424 participants with SCI. $^{8}$ In that cross-sectional study, the severity of NBD was associated with time since injury, even when adjusting for advancing age. ${ }^{8}$ Following the same cohort for 10 years, we found an increase in the severity of constipation and a decrease in QoL. ${ }^{19}$ The primary aim of the present study was to compare bowel function and methods for bowel management in 2015 with those of the same individuals in 1996 and in 2006. Our main hypothesis was that there would be a gradual increase in the severity of constipation. Also, we speculated that new treatment modalities introduced would have altered the pattern of treatment.

\section{MATERIALS AND METHODS}

In the original 1996 study, $424(72 \%)$ of the 589 members of 'RYK' responded. ${ }^{8}$ In 2006, 284 of the original group were alive and $159(56 \%)$ responded. ${ }^{19}$ As of 2015, 178 of the original 589 members were alive and still members of the organization.

A detailed questionnaire, nearly identical to the one used in 1996, was mailed to the surviving members. As opposed to 1996, the present questionnaire did not include items about bladder function, but an item about colorectal surgery performed since 1996 was added.

The present questionnaire consisted of 28 questions describing age, gender, time since lesion, constipation (five items), obstructed defaecation (five items), faecal incontinence (seven items) and QoL (seven items). Nine questions

\footnotetext{
${ }^{1}$ Neurogastroenterology Unit, Department of Hepatology and Gastroenterology, Aarhus University Hospital, Aarhus, Denmark; ${ }^{2}$ Pelvic Floor Unit, Department of Surgery, Aarhus University Hospital, Aarhus, Denmark and ${ }^{3}$ Danish Pain Research Centre, Department of Clinical Medicine, Aarhus University, Aarhus, Denmark Correspondence: Dr PM Faaborg, Pelvic Floor Unit, Department of Surgery, Aarhus University Hospital, Aarhus C Dk-8000, Denmark.

E-mail: pmfaaborg@gmail.com

Received 8 June 2016; revised 23 January 2017; accepted 24 January 2017; published online 14 March 2017
} 
regarding abdominal pain and discomfort were also included but these results are published elsewhere. ${ }^{20}$ The validity and reproducibility of the questionnaire were tested in the original 1996 study. ${ }^{8}$ Members who did not respond after a 3-week period were sent a reminder, encouraging them to participate. Ethic approval is not required by Danish law for studies of this nature that only involve questionnaires.

All data for participants responding in 1996, 2006 and 2015 were entered using EpiData EntryClient and each entry was double-checked to reduce the risk of typing errors.

Statistical analyses were performed using STATA (StataCorp., College Station, TX, USA). Results from 2015 were compared with the corresponding data from 1996 and 2006. Pearson $\chi^{2}$-tests were to compare differences between groups while McNamara tests and Wilcoxon tests were used for comparisons of paired data. $P<0.05$ was considered statistically significant.

\section{RESULTS}

Study cohort

Among the 178 surviving 1996 members, 138 (78\%) responded in 2015. Combining those responding both in 1996 and in 2015 left $109(61 \%)$ who had responded on both occasions (Table 1). This included 103 who had also responded in 2006. Figure 1 displays participants' flow from 1996, 2006 to 2015.

\section{Constipation}

The proportion of respondents using more than $30 \mathrm{~min}$ to defecate increased significantly from 1996 to 2015 (Table 2). Accordingly, more considered themselves to be constipated and more took oral laxatives (Table 2). Please refer to Figures 2 and 3 for a schematic presentation of data. There was no significant change in frequency of defaecation, use of digital evacuation, help needed for bowel management or use of enemas. Constipation as a cause of some or major restrictions on daily life did not significantly change either.

\section{Faecal incontinence}

As shown in Table 3, there had been no significant change in faecal incontinence among our study population, except for an increased use of diapers for faecal incontinence.

\section{Neurogenic bowel dysfunction and QoL}

The proportion of respondents reporting that constipation had some or major impact on their QoL did not significantly change (Table 4). Nor were there any significant changes regarding the effects of general bowel dysfunction, bowel evacuation or faecal incontinence on QoL (Table 4).

\section{Surgery}

Of the 109 respondents, 22 had undergone surgery related to NBD $(20 \%)$. Eleven $(10 \%)$ had a stoma, including $5(5 \%)$ with colostomy, $3(3 \%)$ with appendicostomy, $1(1 \%)$ with iliostomy and $2(2 \%)$ with unspecified stomas.

\section{DISCUSSION}

We followed a cohort of people with SCI for almost two decades. At follow-up, most participants were mid-aged or elderly (median 55

Table 1 Demographics of the participants with spinal cord injury responding to the questionnaires in both 1996 and 2015

\begin{tabular}{lc} 
Item & $\begin{array}{c}\text { Participants responding in } 1996 \text { and } 2015 \\
(\mathrm{n}=109)\end{array}$ \\
\hline $\begin{array}{l}\text { Gender } \\
\text { Female }\end{array}$ & $26(24 \%)$ \\
Male & $83(76 \%)$ \\
& \\
Median age, years (IQR) & $55(49-63)$ \\
Median time since injury, years (IQR) & $28(24-34)$ \\
& \\
Cause of lesion & \\
Trauma & $75(69 \%)$ \\
Spinal surgery & $4(4 \%)$ \\
Myelomeningocele & $5(5 \%)$ \\
Other & $25(23 \%)$ \\
& \\
Level of injury & \\
Cervical & \\
Thoracic & $10(9 \%)$ \\
Lumbar & $33(30 \%)$ \\
Severity of injury & $67(61 \%)$ \\
Complete lesions & \\
Incomplete lesions & \\
\hline
\end{tabular}

Abbreviation: IQR, interquartile range.

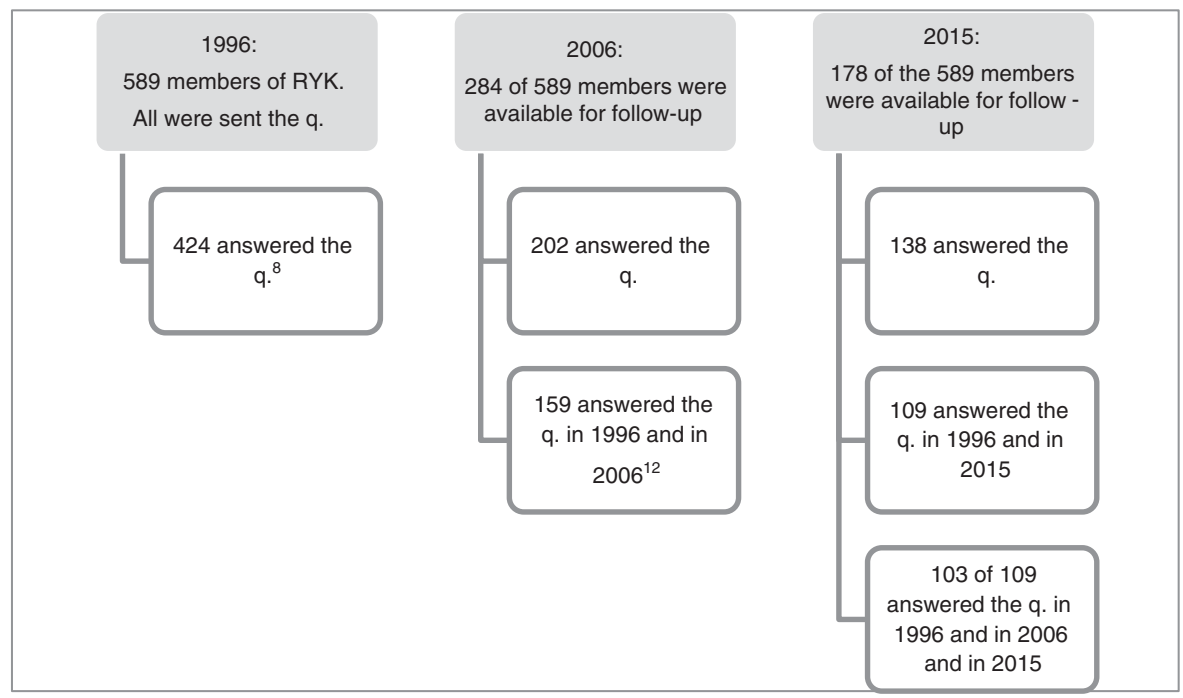

Figure 1 Flow chart of participants responding to the questionnaire in 1996, 2006 and 2015. 
Table 2 Constipation-related symptoms in participants with spinal cord injury responding in 1996, 2006 and 2015

\begin{tabular}{|c|c|c|c|c|}
\hline & 1996 & 2006 & 2015 & Level of significance \\
\hline Need more than 30 min to defecate & $23(21 \%)$ & $32(31 \%)$ & $43(39 \%)$ & $P<0.01^{\mathrm{a}}$ \\
\hline Defaecation less than every second day & $11(10 \%)$ & $19(18 \%)$ & $17(16 \%)$ & NS \\
\hline Digital evacuation or stimulation at least once a week & $56(51 \%)$ & $57(55 \%)$ & $62(57 \%)$ & NS \\
\hline \multicolumn{5}{|l|}{ Use of laxatives } \\
\hline Tablets & $24(22 \%)$ & $20(19 \%)$ & $41(38 \%)$ & $P<0.05^{\mathrm{a}, \mathrm{b}}$ \\
\hline Drops & $11(10 \%)$ & $11(11 \%)$ & $22(20 \%)$ & $P<0.05^{a, b}$ \\
\hline Use of enema & $26(24 \%)$ & $21(20 \%)$ & $20(18 \%)$ & NS \\
\hline Need of help for bowel management & $33(30 \%)$ & $31(30 \%)$ & $40(37 \%)$ & NS \\
\hline Constipation causes some or major restrictions on daily life & $14(13 \%)$ & $12(12 \%)$ & $19(17 \%)$ & NS \\
\hline Do you consider yourself to be somewhat or much constipated & $19(17 \%)$ & - & $31(28 \%)$ & $P<0.01^{a}$ \\
\hline
\end{tabular}

Abbreviation: NS, not significant.

a $P$-values when comparing data from the 109 participants responding both in 1996 and 2015

${ }^{b} P$-values when comparing data from the 103 participants responding both 2006 and 2015 .

\section{Constipation}

$\square$ Persons $(\%)$ needing $>30$ minutes to defecate

$\square$ Persons (\%) considering themselves to be constipated $p<0.01$

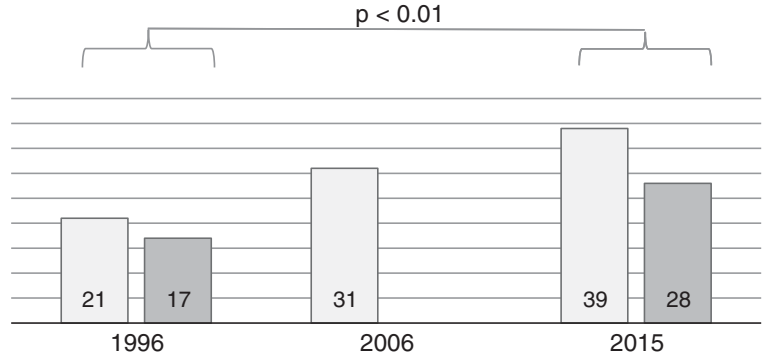

Figure 2 Increases in constipation-related symptoms from 1996 to 2015. Data from 109 participants responding both years.

years) and all had lived with the consequences of SCI for a long time (median 28 years). The changes in bowel function and their consequences for quality of life probably reflect several factors; including advancing age and time since injury, changes in clinical practice, and the ability to cope with a chronic condition. During the 19 years of follow-up, the self-perceived severity of constipation had worsened considerably from 17 to $28 \%$ considering themselves somewhat or much constipated. This is consistent with the fact that the proportion spending more than $30 \mathrm{~min}$ on bowel management had increased significantly from 21 to $39 \%$. It is well known that time for bowel care is closely associated with self-reported impact on quality of life. ${ }^{14}$ Surprisingly, there was not a clear relationship between severe constipation and poor self-reported QoL. The reason for this discrepancy remains obscure, but it could reflect that participants become more willing to accept the consequences as they get older and have lived with the condition for decades.

Faecal incontinence is the single-bowel symptom that has the most severe consequences for daily activities and QoL. ${ }^{14}$ Thus, episodes of incontinence at least once per month tend to restrict daily activities. In our cohort, the proportion having faecal incontinence at least once per month remained stable as did the degree of self-reported QoL.

Our study did not determine whether the increased severity of constipation is caused by time since injury per se or by advancing age. However, in our previous research, we found no association between

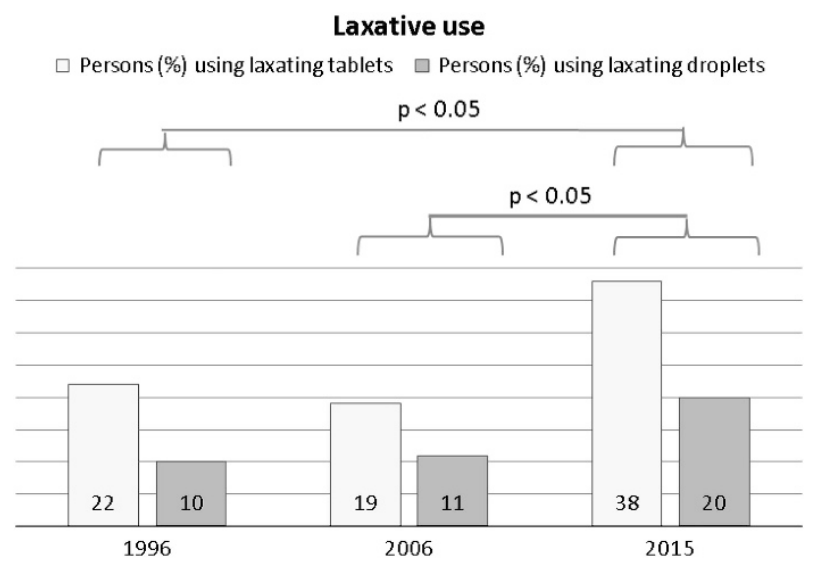

Figure 3 Increases in the use of laxatives from 1996 to 2015. A number of 109 participants responded in 2015 and in 1996; 103 participants responded in 2015 and in 2006.

age and constipation when correcting for time since injury. ${ }^{8}$ An ongoing multicentre study from the Netherlands will further address this question. ${ }^{20}$ It is well known from the general population that advancing age is associated with a higher prevalence of constipation $^{21-23}$ and faecal incontinence. ${ }^{21,24}$ The aim of the present study was not to compare bowel symptoms between participants with SCI and the general population. Thus, we had no control group of able-bodied participants. The prevalence of constipation and faecal incontinence were, however, much higher than previously reported among the general population ${ }^{21-24}$ and closer to those reported for people with SCI. ${ }^{7,9,10}$

The frequency of defaecation did not change over time. This is most likely because most individuals with SCI need to induce defaecation by digital stimulation or transanal irrigation. Hence, they tend to schedule defaecation into a regular routine. We did, however, expect that the increasing severity of bowel symptoms and the introduction of new treatment modalities would have changed other aspects of daily bowel care. This was not so, but experiences from other centres indicate that strategies for management of NBD are very difficult to change. ${ }^{25}$

Bowel care took participants more time to complete but the percentage using digital stimulation or evacuation remained almost constant both at the 10-year follow-up in 2006 and at the 19-year 
Table 3 Faecal incontinence in participants with spinal cord injury responding in 1996, 2006 and 2015

\begin{tabular}{|c|c|c|c|c|}
\hline & 1996 & 2006 & 2015 & Level of significance \\
\hline Faecal incontinence at least once every month & $19(17 \%)$ & $13(13 \%)$ & $21(19 \%)$ & NS \\
\hline Faecal incontinence without notice at least once a month & $11(10 \%)$ & $9(9 \%)$ & $16(15 \%)$ & NS \\
\hline Diapers for faecal incontinence & $4(4 \%)$ & $8(8 \%)$ & $11(10 \%)$ & $P<0.05^{a}$ \\
\hline Flatus incontinence & $42(39 \%)$ & $45(44 \%)$ & $39(36 \%)$ & NS \\
\hline Perianal skin problems & $11(10 \%)$ & $25(24 \%)$ & $21(19 \%)$ & NS \\
\hline Medication to prevent faecal incontinence & $8(7 \%)$ & $1(1 \%)$ & $4(4 \%)$ & NS \\
\hline Faecal incontinence cause some or major restrictions on your everyday life & $14(13 \%)$ & $16(16 \%)$ & $12(11 \%)$ & NS \\
\hline
\end{tabular}

Abbreviation: NS, not significant.

${ }^{a} P$-values when comparing data from the 109 participants responding both in 1996 and 2015.

Table 4 Effects of neurogenic bowel dysfunction on quality of life

\begin{tabular}{|c|c|c|c|c|}
\hline QoL and overall bowel consequences & 1996 & 2006 & 2015 & Level of significance \\
\hline Colorectal dysfunction causes some or major restriction on general condition & $28(26 \%)$ & $32(31 \%)$ & $36(33 \%)$ & NS \\
\hline Constipation cause some or major restriction on your $\mathrm{QoL}$ & $17(16 \%)$ & $12(12 \%)$ & $25(23 \%)$ & NS \\
\hline Difficult bowel evacuation cause some or major restriction on your QoL & $27(25 \%)$ & $20(19 \%)$ & $28(26 \%)$ & NS \\
\hline Faecal incontinence cause some or major restriction on your QoL & $16(15 \%)$ & $16(16 \%)$ & $15(14 \%)$ & NS \\
\hline
\end{tabular}

Abbreviations: NS, not significant; QoL, quality of life.

follow-up in 2015. Surprisingly, the proportion using enemas did not increase despite evidence for its effect against NBD. ${ }^{12}$ It appears that participants tend to continue with digital stimulation or mini enema for bowel emptying for decades and add oral laxatives if constipation worsens. This might be unfortunate, as transanal irrigation can reduce time spent on bowel care. ${ }^{12}$ However, participants included in a randomized trial of transanal irrigation versus standard bowel care had severe NBD and they may not be representative of the wider population of individuals with SCI. ${ }^{12}$ Also, about $50 \%$ of patients introduced to transanal irrigation abandon treatment within the first 3 years. ${ }^{26}$ It is thus possible that some respondents in our study may have tried transanal irrigation but abandoned it.

The proportion of respondents having undergone surgery for NBD during the 19 years was as high as $20 \%$. This includes minor procedures, but still, $10 \%$ had a stoma for bowel care. Appendicostomy, colostomy or ileostomy are only indicated in patients with unsatisfactory response to conservative bowel care, ${ }^{17,18}$ and especially in elderly immobile patients with poor hand function. In that patient group, a stoma may alleviate symptoms significantly. 27,28 Only $9 \%$ of respondents at follow-up had cervical lesions, but the relatively high age may help explain the high frequency of stomas. Sacral anterior root stimulation ${ }^{29}$ and sacral nerve stimulation may have an effect in highly selected patients with NBD. ${ }^{13}$ However, none of the respondents in the present study had undergone treatment with nerve stimulation.

Our study population has changed since the original 1996 study. Notably, the level of injury was lower. This reflects the fact that people with tetraplegia have an expected lifespan 10 years shorter than those with paraplegia. The difference could affect the external validity of our results, but in long-term studies the changes in study population will inevitably depend on their life expectancies. We would, however, not expect that people with cervical lesions have less severe bowel dysfunction than other people with SCI. ${ }^{8}$ At follow-up, $61 \%$ had lumbar lesions. On the basis of our questionnaire, we were not able to distinguish between participants with conal or cauda equina lesions and those with supraconal lesions. The pattern of bowel dysfunction differs between the two groups, ${ }^{3,6}$ but the recommended methods for bowel care are the same. ${ }^{17,18}$

Selection bias could have affected our results. It is unknown if persons with severe bowel dysfunction are more or less willing to respond. Furthermore, our results were based on self-report. Objective measures to confirm the individual perceptions would have strengthened the study. Many of those participating in 1996 had died in 2015. Thus, the number of respondents became significantly lower increasing the risk of type II errors. That is, missing differences that may be important.

In conclusion, constipation worsened significantly over time in our cohort of people with SCI with increasing numbers considering themselves constipated. In spite of this, strategies for daily bowel management have remained surprisingly stable for decades. Increasing numbers of people added oral laxatives or chose to have a stoma rather than using transanal irrigation.

\section{DATA ARCHIVING}

There were no data to deposit.

\section{CONFLICT OF INTEREST}

The authors declare no conflict of interest.

\section{ACKNOWLEDGEMENTS}

We thank 'RYK', the Danish organization for persons with spinal cord injury, for practical assistance with the study.

1 Menardo G, Bausano G, Corazziari E, Fazio A, Marangi A, Genta V et al. Large-bowel transit in paraplegic patients. Dis Colon Rectum 1987; 30: 924-928.

2 Krogh K, Mosdal C, Laurberg S. Gastrointestinal and segmental colonic transit times in patients with acute and chronic spinal cord lesions. Spinal Cord 2000; 38: 615-621.

3 Krogh K, Olsen N, Christensen P, Madsen JL, Laurberg S. Colorectal transport during defecation in patients with lesions of the sacral spinal cord. Neurogastroenterol Motil 2003; 15: 25-31. 
4 Rasmussen MM, Krogh K, Clemmensen D, Bluhme H, Rawasdeh Y, Christensen P. Colorectal transport during defecation in subjects with supraconal spinal cord injury. Spinal Cord 2013; 51: 683-687.

5 MacDonagh R, Sun WM, Thomas DG, Smallwood R, Read NW. Anorectal function in patients with complete supraconal spinal cord lesions. Gut 1992; 33: 1532-1538.

6 Krogh K, Mosdal C, Gregersen H, Laurberg S. Rectal wall-properties in patients with acute and chronic spinal cord lesions. Dis Colon Rectum 2002; 45: 641-649.

7 Glickman S, Kamm MA. Bowel dysfunction in spinal-cord-injury patients. Lancet 1996; 347: 1651-1653.

8 Krogh K, Nielsen J, Djurhuus JC, Mosdal C, Sabroe S, Laurberg S. Colorectal function in patients with spinal cord lesions. Dis Colon Rectum 1997; 40: 1233-1239.

9 De Looze D, Van Laere M, De Muynck M, Beke R, Elewaut A. Constipation and other chronic gastrointestinal problems in spinal cord injury patients. Spinal Cord 1998; 36: 63-66.

10 Harari D, Sarkarati M, Gurwitz JH, McGlinchey-Berroth G, Minaker KL. Constipationrelated symptoms and bowel program concerning individuals with spinal cord injury. Spinal Cord 1997; 35: 394-401.

11 Finnerup NB, Faaborg P, Krogh K, Stahlin-Jensen T. Abdominal pain in long-term spinal cord injury. Spinal Cord 2008; 46: 198-203.

12 Christensen P, Bazzocchi G, Coggrave M, Abel R, Hulting C, Krogh K et al. A randomized controlled trial of transanal irrigation versus conservative bowel management in spinal cord injured patients. Gastroenterology 2006; 131: 738-747.

13 Holzer B, Rosen HR, Novi G, Ausch C, Hölbling N, Schiessel R. Sacral nerve stimulation for neurogenic faecal incontinence. Br J Surg 2007; 94: 749-753.

14 Krogh K, Christensen P, Sabroe S, Laurberg S. The neurogenic bowel dysfunction score Spinal Cord 2006; 44: 625-631.

15 Krogh K, Perkash I, Stiens SA, Biering-Sørensen F. International bowel function basic spinal cord injury data set. Spinal Cord 2009; 47: 230-234.

16 Krogh K, Perkash I, Stiens SA, Biering-Sørensen F. International bowel function extended spinal cord injury data set. Spinal Cord 2009; 47: 235-241.

17 Krassioukov A, Eng JJ, Claxton G, Sakakibara BM, Shum S. Neurogenic bowe management after spinal cord injury: a systematic review of the evidence. Spinal Cord 2010; 48: 718-733.
18 Hughes M. Bowel management in spinal cord injury patients. Clin Colon Rectal Surg 2014; 27: 113-115.

19 Faaborg PM, Christensen P, Finnerup N, Laurberg S, Krogh K. The pattern of colorectal dysfunction changes with time since spinal cord injury. Spinal Cord 2008; 46: 234-238.

20 Nielsen SD, Faaborg PM, Christensens P, Krogh K, Finnerup NB. Chronic abdominal pain in long-term spinal cord injury: a follow-up study. Spinal Cord 2017; 55 290-293.

21 Adriaansen JJ, van Asbeck FW, Lindeman E, van der Woude LH, de Groot S, Post MW. Secondary health conditions in persons with a spinal cord injury for at least 10 years: design of a comprehensive long-term cross-sectional study. Disabil Rehabil 2013; 35 1104-1110.

22 Pare P, Ferrazzi S, Thompson WG, Irvine EJ, Rance L. An epidemiological survey of constipation in canada: definitions, rates, demographics, and predictors of health care seeking. Am J Gastroenterol 2001; 96: 3130-3137.

23 Stewart WF, Liberman JN, Sandler RS et al. Epidemiology of constipation (EPOC) study in the United States: relation of clinical subtypes to sociodemographic features. $A m \mathrm{~J}$ Gastroenterol 1999; 94: 3530-3540.

24 Ditah I, Devaki P, Luma HN, Ditah C, Njei B, Jaiyeoba C et al. Prevalence, trends, and risk factors for faecal incontinence in United States adults, 2005-2010. Clin Gastroenterol Hepatol 2014; 12: 636-643.

25 Goetz LL, Nelson AL, Guihan M, Bosshart HT, Harrow JJ, Gerhart KD et al. Provider adherence to implementation of clinical practice guidelines for neurogenic bowel in adults with spinal cord injury. J Spinal Cord Med 2005; 28: 394-406.

26 Faaborg PM, Christensen P, Kvitzau B, Buntzen S, Laurberg S, Krogh K. Long-term results of transanal irrigation for neurogenic bowel dysfunction. Spinal Cord 2009; 47: 545-549.

27 Randell N, Lynch AC, Anthony A, Dobbs BR, Roake JA, Frizelle FA. Does a colostomy alter quality of life in patients with spinal cord injury? A controlled study. Spinal Cord 2001; 39: 279-282.

28 Coggrave MJ, Ingram RM, Gardner BP, Norton CS. The impact of stoma for bowe management after spinal cord injury. Spinal Cord 2012; 50: 848-852.

29 Rasmussen MM, Kutzenberger J, Krogh K, Zepke F, Bodin C, Domurath B et al. Sacral anterior root stimulation improves bowel function in subjects with spinal cord injury. Spinal Cord 2015; 53: 297-301. 